\title{
Optical Transmission Problem Identified
}

National Cancer Institute

\section{Source}

National Cancer Institute. Optical Transmission Problem Identified. NCI Thesaurus. Code C92090.

Problems with the device's ability to pass light energy. 